\title{
Official pedagogic identities from South African policy - some implications for mathematics teacher education practice
}

\author{
Diane Parker \\ University of KwaZulu-Natal \\ parkerdc@ukzn.ac.za
}

In South Africa the National Curriculum Statement for Grades 10 - 12 (General): Mathematics (DoE, 2003) together with the Norms and Standards for Educators (DoE, 2000a) are key policy documents that provide the official basis for mathematics education reform and for the construction of new pedagogic identities. In this paper I use a framework based on the work of Bernstein (1996, 2000) to theorise the construction of pedagogic identities. I use this to build on Graven's (2002) description of the new official pedagogic identity of the South African mathematics teacher, and on Adler et al. (2002) and others to raise questions related to teacher knowledge and the challenges of developing specialist mathematics teacher identities through initial teacher education programmes.

\section{Introduction}

The past decade has been characterised by major transformations in South African society. There has been a concerted effort by the state to radically transform the apartheid educational terrain through new policies and practices. A major political project has been to radically transform the pedagogic identities of teachers working within the system and to produce new teachers who meet these transformation ideals.

A major concern of education reform is to change "the bias and focus of official knowledge" and to construct new pedagogic identities in teachers and learners. The new pedagogic identity emerges as reflections of differing discursive bids "to construct in teachers and students a particular moral disposition, motivation and aspiration, embedded in particular performances and practices" (Bernstein, 2000: 65).

New policy statements overtly give details of the kind of teacher and learner envisaged by the new curriculum:

... (T)eachers and other educators are key contributors to the transformation of education in South Africa. The National Curriculum Statement Grades 10-12 ... visualise teachers who are qualified, competent, dedicated and caring. They will be able to fulfil the various roles outlined in the Norms and Standards for Educators.

And

The kind of learner ... is one who will be imbued with the values and act in the interests of a society based on respect for democracy, equality, human dignity and social justice as promoted in the Constitution. ... (L)earners emerging from the Further Education and Training band must ... have access to, and succeed in, lifelong education and training of good quality; demonstrate an ability to think logically and analytically, as well as holistically and laterally; and be able to transfer skills from familiar to unfamiliar situations. (DoE, 2003: 5)

These quotations, from the introduction to the National Curriculum Statement for Grades $10-12$ (General): Mathematics (NCSM), the curriculum for the schooling sector of Further Education and Training (FET) ${ }^{1}$ in South Africa, give a symbolic picture of 'ideal' teachers and learners. They point to the vision of the kind of moral disposition, motivation and aspiration desired in teachers and learners by the South African state and more generally by South African society. The role of teachers as agents of transformation for a new democratic order is clearly articulated. The NCSM goes on to describe some of the particular performances and practices in which these should be embedded, and indicates both the nature of mathematical knowledge to be acquired and how it should be acquired and assessed.

Other policy, the Norms and Standards for Educators (NSE) (DoE, 2000a), describes what it means to be a "competent professional educator" 1 South Africa schooling is divided into 'bands'. Early Childhood
Education (ECE) - pre-school; General Education and Training (GET)
- grades 1 to 9; and Further Education and Training (FET) - grades 10
to 12 . 


\section{Diane Parker}

in South Africa. It provides a vision of a professional teacher who is able to integrate a complex set of seven teacher roles with social, economic and moral responsibility. The roles include being: mediators of learning; interpreters and designers of learning programmes and materials; leaders, administrators and managers; scholars, researchers and lifelong learners; community members, citizens and pastors; assessors; and subject specialists. The NSE describes in generic terms the "applied and integrated competences" that constitute the roles. These are: foundational competence (knowing that/what); practical competence (knowing how); reflexive competence (knowing why), integrated so that teachers know what to do, why it should be done, when to do it, and how to do it in the moment of practice.

The Criteria for Recognition and Evaluation of Qualifications (Criteria) (DoE, 2000b), is a further policy, which compliments the NSE. The NSE has a largely symbolic function presenting a holistic picture of an ideal teacher towards which teacher education curricula should aim. The Criteria plays a largely regulative function making it mandatory for higher education institutions involved in teacher education to design curricula in line with the NSE. From the perspective of the Department of Education (DoE), these norms, standards and criteria indicate to all providers (public and private) the kinds of teacher qualifications and learning programmes that the DoE will consider for employment. And for the public providers, the kinds of programmes and qualifications the DoE will consider for funding (Parker, 2003).

The NSE together with the NCSM projects a symbolic image of what is expected of mathematics teachers in the new reformed system. This is an official image of a desired pedagogic identity, a policy image, rather than a constructed reality based in practice. The competent professional mathematics teacher in post-apartheid South Africa is characterised through these images and is expected to be produced though curriculum reform in teacher education, as regulated through the Criteria. Teacher education is thus charged with a major challenge: to produce new teachers in this new image through newly designed pre-service and in-service teacher qualifications, and so, to institutionalise the 'bias and focus' of official knowledge.

How do mathematics South African teacher education providers respond to this transforming context and to the challenges presented by these new policies? What positions do they take in response to the policy, and how do they design and organise their mathematics teacher education curricula so as to produce new specialist mathematics teachers for this new social and political context? These are some questions that frame the major research project from which the current paper emerges. In order to answer these and other related questions, is was necessary to break the wider research project into various phases. The first phase, reported in Parker and Adler (2005), focused on an investigation of the institutional and policy changes that occurred in relation to teacher education during the first ten years of the post-apartheid order, and theorised the pedagogic space produced for mathematics teacher education within this transforming context. The issue of specialising the consciousness of specialist mathematics teachers ${ }^{2}$ through such teacher education programmes led to the theorisation of pedagogic identities and knowledge discourses in the design of teacher education curricula aimed at producing teachers in and for this new context. An analysis of key policy documents including the NSE, the Criteria and the NCSM was necessary as a basis for analysing the official pedagogic identity projected from South African policy. In particular a detailed analysis of the NCSM (Parker, forthcoming) provides a resource for producing a description of the mathematical identities projected from South African policy described in the current paper. The second phase of the project, reported in Parker (2006), involved a comprehensive survey of all specialist mathematics teacher education programmes offered by higher education institutions in South Africa, so as to investigate how various institutional providers of mathematics education responded to the changes. In particular what knowledge resources and practices they have selected, how they have organised these in their curricula and what pedagogic identities they have attempted to institutionalise through their initial mathematics teacher education programmes. A third phase of the project, still to be reported, focuses on case studies selected on the basis of the survey.

This paper is located within the first phase of the wider project. It outlines the context of teacher education reform in South Africa, briefly theorises the notion of 'pedagogic identity' and provides an analysis of the official pedagogic identity of

\footnotetext{
${ }^{2}$ When I refer to specialist mathematics teachers in this paper I am referring to teachers for grades 10-12 of FET. Teachers for the various phases of the GET are more often identified as generalists, and would possibly require a different type of mathematical education from that which is suggested here.
} 


\section{Official pedagogic identities from South African policy - some implications for mathematics teacher education practice}

specialist FET mathematics teachers in South Africa, projected by policy. The official pedagogic identity is discussed in the light of debates in the field around knowledge for specialist mathematics teaching and teacher learning. Tensions between different demands produce challenges for mathematics teacher educators in relation to the way in which they could construct their curricula. How they select and privilege knowledge and practices for teacher learning will have consequences for the construction of a specialised identity of 'mathematics teacher' in and for South Africa within this new context.

\section{The context of teacher education in South Africa}

Teacher education has undergone rapid transformation that has included a delocation and relocation of pedagogic practices from colleges of education regulated and controlled by the state, to relatively autonomous universities and technikons located in the higher education sector. This movement has created a space for mathematics teacher educators/researchers and mathematicians to play a major reform role by designing new curricula (criteria) for the development of new mathematics teacher identities (Parker and Adler, 2005).

In the terms of the NSE the 'specialist role' is marked out as the "the overarching role into which the other roles are integrated, and in which competence is ultimately assessed" (DoE, 2000a: 12). In terms of initial qualifications for FET mathematics teachers, there is no prescription of what ought to be taught, how it ought to be taught, or what "the disciplinary basis of content knowledge, methodology and relevant pedagogic theory" (ibid.: 28) is in substantive terms. It is left up to the teacher educational professionals to produce the criteria for the specialisation. The policy sees FET teaching as a specialist domain and specifies the possibility of providing single subject (discipline-based) qualifications. This produces the possibility of focused qualifications designed to integrate highly specialised knowledge for developing mathematics teachers.

There are two ways to qualify as a FET mathematics teacher in South Africa: A three-year general formative degree with at least two years study in mathematics, followed by a professional certificate in education (PGCE), or a new undergraduate Bachelor of Education (B.Ed) which integrates the academic and professional components into a four-year degree. I am interested in the possibilities inherent within the field for the development of initial mathematics teacher identities through a specialist B.Ed programme, particularly in the potential for different forms of specialised curricula to produce different forms of "specialist consciousness" (Bernstein, 1996, 2000) in mathematics teachers.

In South Africa, there are multiple dimensions to this teacher education task. As Adler (2004: 6) points out, we work in a "socio-cultural and political context deeply scarred by apartheid education". In the field of mathematics the unequal distribution of knowledge and 'ability' is starker than in most areas of the school curriculum, and is a product of unequal opportunities under apartheid. The National Strategy for mathematics and science (DoE, 2001: 12) highlights the dismal performance of black African candidates in mathematics. In the interests of transformation it is necessary to create access routes into mathematics teaching for students who would not normally 'make the grade' for entry into university mathematics courses. This is a major challenge for teacher educators: it is not only necessary to develop an identity as 'mathematics teacher', it will also be important to develop an identity as 'able mathematics learner'.

\section{Theorising pedagogic identities: official and local}

Theoretically, pedagogic identities are 'forms of consciousness', and any particular educational reform represents an approach to regulating and managing moral, cultural and economic change, which are expected to become the lived experiences of teachers and students, through the shaping of consciousness (Bernstein, 2000).

For Bernstein, the power (classification) and control (framing) ${ }^{3}$ relations of any pedagogic practice regulate the acquisition of pedagogic identity. The selections of knowledge(s), performances and practices and their evaluation rules (criteria for recognition and realisation) ${ }^{4}$ relay a particular social order and way (mode) of knowing and being, whether explicitly or tacitly. The acquisition of the specialised consciousness produces particular orientations to meaning - ways of recognising and realising what is constituted as the 'legitimate text'. This comes "to have the force

\footnotetext{
3 Classification and framing are key concepts for Bernstein (1990, 1996, 2000). Classification "provides us with our voice and the means of its recognition" and framing is "the means of acquiring the legitimate message". Classification is a product of power and framing of control.

4 According to Bernstein (1990: 15), "( r)ecognition rules create the means of distinguishing between and so recognising the speciality that constitutes a context, and realisation rules ... regulate the creation and production of specialised relationships internal to that context."
} 


\section{Diane Parker}

of the natural order and the identities that it constructs are taken as real, as authentic, as integral, as the source of integrity" (Bernstein, 1996: 21). Educational reforms require changes in the recognition and realisation rules of the pedagogic practice and therefore can be seen as "the outcome of the struggle to produce and institutionalise particular identities" (Bernstein, 2000: 66).

For Bernstein (2000) local identities are social identities, constructed through social location. These vary with age, gender, social class, occupational field and economic and symbolic control. They are not necessarily stable positions and shifts can be expected depending on maintaining the discursive/economic base of the identity. This fits with Castells's (1997) concept of identity as a source of individual meaning and experience that should be distinguished from social 'roles'. Roles are defined by norms structured by institutions and organisations of society, whereas identities are sources of meaning for the actor, constructed through a process of individualisation. Identities organise meaning and roles organise functions. Meaning is the symbolic identification by social actors of the purpose of their actions.

This helps point to the difference between an official pedagogic identity and a local pedagogic identity of a teacher. The official pedagogic identity is constructed through descriptions of what 'ought to be' based on particular projections by institutions of the roles, knowledge codes and social modes individuals ought to take up (official knowledge). Local pedagogic identity is constructed sociologically in local educational and historical contexts. Thus while official teacher identities can be designed on the basis of 'teacher roles', local teacher identities cannot - teacher identities emerge, enabled or constrained, within the pedagogic context (Graven, 2002).

In this understanding local pedagogic identities are not individual (cognitive) attributes, neither are they simply constructed politically or as a result of a curriculum prescription, they are constructed through an interplay of the 'voice-message' system (Bernstein, 1996), an interplay between official and local knowledge and practices within an educational community. Thus the 'legitimate' text (e.g. what is accepted as 'good mathematics teaching practice') is constructed through a relay between specialists in the field of teacher education, novice teachers, and experienced teachers within the social contexts of educational practice. Teacher identity is therefore embedded in the social practices of an education community within 'a particular social order' and develops in this context through relationships "of reciprocal recognition, support, mutual legitimisation and finally through negotiated collective purpose" (Bernstein, 1996: 73).

According to Bernstein (1996, 2000) individual pedagogic identities are constructed both inwardly and outwardly. The introjected identity faces inwardly and is most often related to the acquisition of stable inner loyalties related to esoteric forms of thinking and doing, for example, working in principled ways with disciplinary knowledge, or developing a therapeutic identity related to notions of child development and internal, or sacred, religious and cultural values. The projected identity faces outwardly and is most often related to external demands from the state and the market for producing particular kinds of citizens, and for regulating and controlling them. The challenge for teacher educators is to design programmes that enable the construction of introjected identities leading to 'good mathematics' and 'good mathematics teaching'. This needs to happen within the economic constraints and competitive environment of the higher education sector, and should be balanced with projected identities that meet some of the transformational ideals of the state: particularly the need to provide access to powerful mathematics to a wider range of South African students.

What is considered 'good mathematics' and 'good mathematics teaching' practice within these contexts becomes a major issue: who defines what this means, on what basis is that decision made, and how is access to the criteria (recognition and realisation rules) for these new notions of mathematics and mathematics teaching made possible? Any notion of 'good practice' that a particular institution attempts to institute will have an ideological basis, and the particular selections of knowledge contents and practices together with how these are made available to students, can be analysed to identify it. Whether this is an ideology that is based on and driven by political and social concerns, academic and intellectual concerns, or practical and professional concerns, or some combination of these, is of interest and will have consequences for the kind of specialisation of consciousness that may be made possible within the educational context. In a context of the poverty of mathematics education alluded to earlier, this becomes a crucial concern. Improving access to meaningful relationships with powerful forms of mathematics within the schooling system will to a large extent be dependent on producing teachers 


\section{Official pedagogic identities from South African policy - some implications for mathematics teacher education practice}

who have acquired this identity, as interested and able mathematics learners themselves.

The experiences student teachers have, in the mathematics classroom/lecture theatre, the teacher education lecture theatre and out in the school in practice will influence their specialisation of consciousness. Whether their understanding of the nature of mathematics, their relationship with the subject matter, and what they consider and construct as 'good' mathematics teaching practices, is substantially changed from prior, and probably internalised, notions forged during their 12 years of schooling and determined by the apartheid educational order or not, becomes a central question underpinning the research project, and will become a focus of the case studies for the third phase of the project mentioned earlier in this paper. In order to investigate how teacher educators in the various institutions have responded to policy and what ideology lies behind the image of 'good practice' they project from their institutions (as embedded within the organisation of their curricula), it was necessary to first analyse the official identities projected from the mathematics curriculum policy. This is the focus of the next section of the paper.

\section{The official pedagogic identity of specialist} mathematics teachers projected from SA policy Policy documents can be analysed to identify the particular 'bias and focus' of official knowledge and to examine the official pedagogic identities they project, and therefore to unpack what it might mean to produce the kind of teacher expected. This could be critically reflected on in terms of research in the mathematics education field to produce a local resource for the construction of curricula for specialist mathematics teachers. A clear picture of the projected official pedagogic identity requires a detailed document analysis. I have insufficient space here to provide details of this document analysis, ${ }^{5}$ and thus simply sketch some of the characteristics of the policy image based on my analysis of the NCSM (Parker, forthcoming). The analysis required working through all four chapters of the NCSM, sentence by sentence, categorising these using a framework based on Bernstein's concepts discussed earlier, and building on work done by Graven (2002).

Graven's (2002) analysis of the official pedagogic identity projected from the South African policy base, focuses on senior phase general education teachers (grades 7-9), and

\footnotetext{
${ }^{5}$ See Parker (forthcoming) for a discussion of the detailed analysis of
} the NCSM. effectively illuminates some of the main differences in the 'outgoing' roles of teachers and their future 'incoming' roles as designed within the new education system. She shows that there is a movement in thinking about teaching and learning within South African education from a performance-based to a competence-based pedagogy, ${ }^{6}$ and from a collection to an integrated knowledge code. ${ }^{7}$ She uses this together with an analysis of specific curriculum statements for the grade 7 to 9 mathematics 'learning area' to identify four different orientations to mathematics, and from this four mathematical roles teachers are expected to fulfil, each with its own mathematical demands. These orientations to mathematics are summarised as: mathematics for critical democratic citizenship; mathematics as relevant and applicable to aspects of everyday life and local contexts; mathematics for its beauty and intrinsic value; mathematics as a way of communicating in, thinking about and viewing the world; and, mathematics as conventions and skills to master in order to gain access to further studies.

My analysis of the new NCSM (Parker, forthcoming) shows that while there are some differences much of Graven's (2002) analysis still holds for the NCSM. The logic of competence (Bernstein, 1996) is clearly visible, particularly in the first chapter of the statement. A shift in approach to mathematics teaching is visible - a socio-constructivist, learner-centred, discussionbased approach is advocated. This is clearly articulated through the reference to the roles of a teacher described in the NSE and the kind of teacher and learner advocated by the curriculum (as mentioned in the introduction to this paper). These role descriptions demand significant changes from teachers in relation to their orientation to knowledge and learning, and in their conception of what it means to teach. In particular,

\footnotetext{
6 Graven draws on Bernstein's (1996) distinction between two pedagogic models underpinning a curriculum: competence based and performance based. In general competence models are directed at what the learner knows and can do at the end of the learning process, whereas performance models focus on specific learning contents and texts. See Bernstein (1996: 58-63) for a useful comparison in relation to: time, space and discourse; orientation to evaluation; pedagogic control; pedagogic text; pedagogic autonomy; pedagogic economy.

7 See Bernstein, 1977, "On the Curriculum". According to Bernstein there are two broad types of curriculum: Collection and integrated, although these can be thought of as a continuum rather than a straight dichotomy. In a collection type the contents stand in a closed relation to each other (bounded and insulated from one another) - here the learner has to 'collect' a group of favoured contents in order to satisfy some criteria of evaluation and classification of knowledge contents is strong. In an integrated type the contents stand in an open relation to one another (blurred boundaries and hybrid) - here the learner follows a course structured around some overarching 'big idea', and
} classification is weakened. 


\section{Diane Parker}

the teacher is projected as a learning mediator: she no longer teaches given content knowledge, she facilitates learning. She is responsible for interpreting and designing learning programmes to meet the needs of her learners - the teacher is expected to interpret the broad outcome descriptions and assessment standards in the new curriculum statements and select contents and learning activities to provide learners with appropriate experiences to achieve the outcomes. The new roles thus place high demands on teachers. Teachers do not teach: they mediate learning through the skilful development and use of learning materials. The control of the pedagogic space is displaced from the teacher towards the text (activity/learning material) and the learner is required to take responsibility for his/her own learning (individually and in groups). This represents a move from directly teaching given texts towards the management of knowledge, learning and learning spaces. Thus there is a shift in the locus of classroom control and a visible flattening of hierarchical relations in the classroom. In other words, a movement towards what Bernstein (1996) describes as invisible pedagogy which he associates with a competence based curriculum.

This is in contrast to the markedly different practices still existing in schools under the old curriculum, where teachers follow a content laden syllabus prescribed by the Department of Education and the curriculum is strongly externally controlled (framed) through a high stakes matriculation examination which focuses on an orientation to received knowledge. ${ }^{8}$ The locus of control is with the teacher and the classroom relations are more hierarchical and authoritarian in Bernstein's (1996) terms, a visible pedagogy is in place which can be associated with a performance based curriculum.

The NCSM document indicates a commitment to integration in general terms as one of the underlying principles of the curriculum:

Integration is achieved within and across subjects and fields of learning. The integration of knowledge and skills across subjects and terrains is crucial for achieving applied competence [... and ...] seeks to promote an integrated learning of theory, practice and reflection. (DoE, 2003: 3)

\footnotetext{
${ }^{8}$ See Boaler (2002) for a useful discussion on connected and received knowledge and the relationships with mathematics that are implied by each.
}

However, a close look at the assessment standards and contents of the NCSM shows that the real emphasis on integration is within mathematics rather than across fields of learning. For example, the idea of 'function' is a key integrating principle. This marks out a significant change in the organisation of the contents of the new FET school mathematics curriculum from the GET curriculum discussed by Graven (2002) or the existing (outgoing) secondary school mathematics curriculum. Mathematics remains fairly strongly classified in relation to contents outside of the field of mathematical sciences, but there is a weakening of classification values within the field itself. Instead of 'topics', such as algebra, trigonometry, geometry and calculus, that were well insulated from one another in the old curriculum and organised vertically, the contents of the NCSM are organised in terms of four learning outcomes Number and Number Relationships; Functions and Algebra; Space, Shape and Measurement; and Data Handling and Probability - and are connected horizontally through mathematical processes such as "making conjectures, proving assertions and modelling situations" (ibid.: 10).

Conceptual progression in the disciplines underpinning the subject mathematics as defined in the NCSM is emphasised and the more overtly political and controversial radical integration aspects of the original GET version discussed by Graven (2002) are de-emphasised. There is a focus on application but in contexts where it is appropriate to the core disciplines that form the 'subject'. This curriculum broadens the focus of school mathematics learning from entry into a single discipline (pure mathematical topics) into a region (the mathematical sciences: mathematics, applied mathematics and mathematical statistics). There is a focus on access to the discourse of abstract mathematical knowledge, its structure and processes for entry into further studies in the mathematical sciences. Each of the components of the mathematical sciences is relatively strongly insulated within the NCMS, i.e. there is a principle of internal classification which enables clear distinctions to be made, for example, between statistics and mathematics, and between mathematics and applied mathematics. Statistics is most strongly insulated appearing in the document under a single outcome: Data Handling and Probability, which is an entirely new area in the FET curriculum. Other previously insulated topics in mathematics are spread across the other three learning outcomes and integrated horizontally in 


\section{Official pedagogic identities from South African policy - some implications for mathematics teacher education practice}

terms of mathematical structures, conventions and processes.

Thus in the NCSM there are significant shifts in the specialised contents and processes to be taught and in the underlying philosophy of the mathematics projected. Mathematics is seen as a fallibilistic discipline (Ernest, 1991), and mathematics learning is seen as relational and meaningful in its own right, and useful and meaningful to life. The NCSM provides a definition of mathematics that projects an image of mathematics as practice, a "human activity practised by all cultures" that enables creative and logical reasoning. It sees mathematical knowledge as constructed by "observing patterns, with rigorous logical thinking, $[\ldots]$ lead(ing) to theories of abstract relations" (DoE, 2003: 9). It is thus a systematic way of seeing the world and thinking about the world using structured abstract principles. Further it is "developed and contested over time through both language and symbols and by social interaction and is thus open to change" (ibid.: 9). Mathematical problem solving is seen as a key element which "enables us to understand the world and make use of that understanding in our daily lives" (ibid.: 9). The idea of empowerment as a purpose of mathematics learning is visible: access to mathematical knowledge empowers learners "to make sense of society" by enabling learners to "respond responsibly and sensibly to personal and broader societal concerns" and to engage "responsibly with quantitative arguments relating to local, national and global issues" (ibid.: 10).

This is a broad conception in which mathematics is characterised as a "discipline in its own right and pursues the establishment of knowledge without necessarily requiring applications in real life" (ibid.: 9). At the same time, it is also specifically emphasised that mathematics is more than a cannon of specialised knowledge contents, "competence in mathematical process skills such as investigating, generalising, and proving is more important than the acquisition of content for its own sake" (ibid.: 9). While there is a focus on application of mathematics, the idea of unproblematic transferability of everyday knowledge into mathematics so prominent in the first version of the GET curriculum (Graven, 2002), is absent - the focus is on the "establishment of proper connections between Mathematics as a discipline and the application of Mathematics in the real world" (DoE 2003: 10, emphasis added). Mathematical modelling is seen as the means to analysing and describing the world mathematically. Other proper connections are in relation to the use of mathematical tools for problem solving in other subject areas, such as physical, social and management sciences.

Thus there is a focus on mathematics as a discipline, a practice and a tool - it is a specialised knowledge form with its own unique conventions, symbolism and structure; it is a specialised practice involving specialist processes of thinking, reasoning, proving; and it is a powerful tool for problem solving in a variety of contexts including mathematical (for example, abstract problem solving) and nonmathematical (for example, as applied in issues of public health, finance, or other subject areas such as the physical sciences). Furthermore, mathematics has a history - it is viewed as socially constructed and therefore as a fallible discipline.

In terms of the pedagogic discourse to be realised at the classroom level the NCSM implies new relationships between teachers and learners and between these actors and the subject matter to be taught - changes in both the instructional and the regulative discourse (the what and how) - both in general terms and in very specific terms in relation to what is seen as legitimate mathematical knowledge (concepts) and ways of knowing it (habits of mind and the regulatory order for its learning). Whereas the earlier curriculum was very much product oriented working on the basis of 'received' knowledge (as discussed by Boaler, 2002) - a hierarchy of concepts, facts and skills expressed as definitions, products and methods to be learnt and practiced - this curriculum is not. It is more practice oriented and focused on producing "connected knowledge". It focuses on the practices of mathematics (e.g. investigating, making conjectures, justifying, generalising, etc.) as well as the skills (e.g. factorising) and the products (e.g. 'laws of exponents'); and on making meaning though problem solving contexts. The implication of this curriculum is that teachers' mathematical identities should be constructed as "connected", they should have "productive dispositions" (Kilpatrick, et al., 2001) towards mathematics and be able to engage in a "dance of agency" (Pickering as used by Boaler, 2002).

This does not seem to be a reform curriculum that is based on 'generic' knowledge and a 'watering down' of mathematics, rather it seems it is a curriculum that is very concerned with mathematics and mathematical ways of being and seeing - but these are not images that are necessarily common in the South African context. The new FET mathematics teacher needs to be 


\section{Diane Parker}

competent in these extended curriculum areas she needs to develop a number of specialised pedagogic identities, each related to a specialist knowledge discourse: an identity as mathematician; applied mathematician, statistician and mathematical historian. Access to the grammar of mathematics, applied mathematics and statistics as distinct knowledge discourses, knowledge about their historical development and ways of coming into being, and the ability to apply these meaningfully to problem solving situations, are a key. These mathematical identities are related to the novice teacher's access to practice in the field of mathematical sciences in and for itself (and not necessarily for the purpose of teaching). They have to do with the novice teacher's growth as an 'able mathematics learner' and thus her development of subject loyalty in relation to the disciplines themselves. It is this loyalty that may be a key to her interest in, involvement in and passion for the mathematical sciences that could, given the appropriate opportunities, become the basis for the development of a different set of identities related to mathematics teaching.

Initial teacher education, through the four-year degree programme, is thus faced with a complex task - a need to provide curricula to create paths for the acquisition of mathematical science discourses for teachers who in their own schooling have probably experienced an impoverished mathematical education. However, the development of these consciousnesses is insufficient for a South African teacher hoping to institute the new curriculum, in particular the requirement that they are able to carry out the teacher roles mentioned at the beginning of the paper. Thus, teachers also need to develop practices for teaching these mathematical discourses as distinct from learning them. That is, in addition to acquiring the criteria (recognition and realisation rules) for these specialised forms of consciousness in the mathematical sciences (in and for themselves), the new teacher needs to develop a specialised pedagogy in relation to each "for the complex task of transforming this knowledge into appropriate opportunities for learning in school" (Adler et al., 2002: 151). And this is related to the mathematical work of teaching in practice and the development of mathematical knowledge for teaching (Ball et al., 2004; Adler and Davis, 2006), a knowledge discourse and its practice, that is different from, and possibly works in an opposite direction to, the discourses and practices of the mathematical sciences. ${ }^{9}$

The changes in the mathematics curriculum represent major shifts for most prospective mathematics teachers whose mathematical identities were constructed under an 'old' (outgoing but still existing) education system (Graven 2002). Teachers are required to implement these new ideals in their classroom practice. This means that they are required to develop new images of 'good practice' for mathematics teaching (recognition rules), and new pedagogic identities (forms of consciousness) that enable them to carry out these practices (realisation rules). Teacher educators will need to construct curricula for producing these outcomes.

In terms of the theoretical ideas introduced earlier, while the curriculum statements can project images of ideal mathematics teachers, these intended identities will not necessarily be acquired. What happens in practice will depend on what occurs in real educational contexts and how the student teachers respond to these. The design of teacher education curricula can only work at the level of officially projected identities. However, these can influence the emergence of new teacher identities through the relations they set up with the particular knowledge discourses and practices they make available. What resources are used as a basis for the specialisation of the consciousness and how these are made available to the student teachers will be a crucial issue. Acquisition of the recognition and realisation rules for a specific practice (say learning mathematics or teaching mathematics) will depend on the evaluation rules of the pedagogic discourse - the criteria of what is seen to be the 'legitimate text'. So a different specialised consciousness could be acquired depending on the selection and organisation of knowledge contents and how they are made available to teachers: i.e. what is recognised as legitimate knowledge and practice, and the pedagogic modes of its transmission.

In terms of the various paths to becoming a teacher in South Africa mentioned earlier, it is in the new four-year B.Ed programme that such a (re)education in the mathematical sciences and in mathematics teaching becomes a possibility - that is, teachers coming to know and work within the

9 See Ball and Bass (2000) for a discussion on the idea that mathematicians work at compressing knowledge, while mathematics teachers need to decompress it; Ball, Bass and Hill (2004) for a discussion on the need for teachers to learn to 'unpack' familiar mathematical ideas; and, Adler and Davis's (2006) extension of this idea in their understanding that teachers are required to unpack mathematical knowledge for the purposes of teaching. 


\section{Official pedagogic identities from South African policy - \\ some implications for mathematics teacher education practice}

mathematical sciences in and for themselves, and, teachers working with transformed school mathematical knowledge within a classroom and knowing and practising mathematics for teaching. Gaining access to these forms of knowledge provides a possibility for breaking the cycle of poverty in mathematics education that is a feature of the South African educational context. Key areas of curriculum contestation in relation to these teacher education tasks are linked to questions of what knowledge should be selected?; how should it be organised in the teacher education curriculum?; and, who should be involved in teaching this selection to teachers. For example, should teachers be taught mathematics relevant to the school curriculum by mathematics educators modelled in a way that they ought to teach it? On the other hand, should they be taught mathematical sciences by academics within the disciplinary departments of the university at a level above school mathematics and possibly divorced from school mathematics? Or would some combination of these be best? In terms of teachers learning to select and transform mathematical knowledge for teaching, similar questions can be asked about mathematics teacher education academics and experienced mathematics teachers. I will not enter into this debate here, but rather signal it as a consideration for further research.

\section{Specialising the consciousness of a mathematics teacher: resources, discourses and criteria for recognition and realisation}

In my wider research project mentioned earlier in the paper, an empirical focus is on identifying the knowledge resources and discourses that teacher educators do select for their specialist mathematics teacher education programmes and the way these are organised, co-ordinated and made available to new teachers within their educational contexts. The major focus is on the production of the criteria for the recognition and realisation of 'good mathematics' and 'good mathematics teaching' practices within the various teacher education programmes across the field in South Africa.

In the context of designing initial four-year teacher education programmes the preceding discussion becomes important. The development of the teacher as an 'able mathematics learner', learning the mathematical sciences in and for themselves and thus developing disciplinary identities, must be part of the initial education programme, particularly in the light of the generally low level of personal mathematical competences developed in our prospective teachers through their prior schooling experiences (Parker, 2004), and the high demands of the new curriculum (Parker, forthcoming).

In the wider research field of mathematics teacher education, learning mathematics (becoming an able mathematics learner and developing loyalty to the subject) is often conflated with learning to teach mathematics (becoming a teacher of mathematics and developing knowledge of teaching and learning mathematics) and practising as a mathematics teacher (becoming a mathematics teacher and using mathematical knowledge for teaching in practice). For example, see Ball and Bass's (2000) criticism of the 'fragmented curriculum' of teacher education programmes in terms of the difference between working as a mathematician (compressing knowledge), which they seem to want teacher education programmes to discard, and working as a teacher (decompressing knowledge) which they want to privilege. Another example is Ensor's (2000) work which is concerned with teachers' mathematics education (and teacher education) practices and not teachers learning mathematics in and for itself. In both types of teacher education mentioned, prior mathematical competence is taken as given. To reiterate, much of the reported work relates to in-service mathematics teacher education, or initial teaching where the teacher has previously developed an identity as 'able learner of mathematics' and a certain level of subject loyalty and hence an identity as 'mathematician'. In the light of this I suggest that teacher educators in South Africa should be careful not to conflate the process of developing the specialist FET mathematics teacher as a learner of mathematics with her development as a learner of mathematics for teaching.

In this paper I do not have space to elaborate on any findings from my wider research project; however I do propose some tentative conclusions for a model based on my initial analysis of research in the field. I suggest that practising mathematics teaching (learning a professional practice) and practising mathematics (learning mathematics) are two distinctly different types of activity related to distinct knowledge discourses (Bernstein, 2000). I propose that initial mathematics teachers require both, particularly in times of reform where new mathematical learning identities and teaching identities need to be formed. Although these are connected discourses, I would suggest they should not be learnt at the same time and in the same space, since they work 


\section{Diane Parker}

in opposite directions (as Ball and Bass, 2000 so clearly show with their discussion on compressing and decompressing mathematical knowledge). I also identify a third distinct discourse, created in the growing research domain of mathematics education, which focuses on developing knowledge about teaching and learning mathematics (learning mathematics education).

Thus there are at least three different mathematically related pedagogic identities that a novice specialist mathematics teacher should develop through any teacher education programme. An identity as a student of mathematical sciences (becoming an able mathematics, applied mathematics and mathematical statistics learner, thinker and actor); an identity as a student of mathematics education (becoming someone interested in learning from research in the field of mathematics teaching and learning); and an identity as a mathematics teacher (becoming someone who can utilise their knowledge to help learners develop productive mathematical identities and be motivated to learn the discipline at higher levels). Each of these identities is a product of access to different knowledge discourses, and in each case recognition and realisation rules for what comes to be seen as the 'legitimate' discourse and its practices need to be developed. Knowledge resources and practices need to be selected and organised in the curriculum for these purposes. A key debate and issue of contention in the empirical field is centred on the extent to which these should be integrated or not in teacher education practice, and related to this who should take responsibility for developing them in teachers (mathematicians/mathematics education specialists/teachers).

The discussion above, leads me to suggest that there are at least three specialist (mathematically related) knowledge discourses that initial teachers need to acquire - each with its own ways of thinking and doing, and different organisational structures (vertical and horizontal) and grammar (strong/weak) (Bernstein, 2000). I suggest that these should be co-ordinated in the teacher education curriculum to bring a "notion of best teaching and learning practice into practice' (an adaptation of Ensor's (2000) language). Each discourse requires a different kind of specialisation, probably best developed at different times and in different spaces, and finally coordinated in the practices of the classroom alongside a competent teacher. In this way, distinctions can be made, boundaries between the different discourses can be set up and transgressed and they can be used as knowledge resources to be recruited in practice. I suggest that the curriculum designed for the construction of each of these identities should be based on knowledge produced in the growing domain of mathematics education research, and not simply on the basis of interpretations of what is 'good' from policy or local teaching experiences and resources.

I do not have space here to elaborate on the possible modalities for the acquisition of each of these identities, to discuss the different types of discourses, nor to theorise what type of specialised consciousness different modalities might produce. That is part of my wider research project, and is left for later dissemination. However, what is clear to me is that each one requires specialised mathematical work and not generic practices, and each one needs to be designed, with careful consideration given to the criteria for the selection of the privileged reservoir for recognising the practice and repertoire for realising the practice (Ensor, 2000).

\section{Conclusion}

What does it mean to know mathematics, to teach mathematics and to develop mathematical and other forms of knowledge and practice for teaching? This is a key question for mathematics teacher educators to ask and extremely difficult to answer in any straightforward manner. However, the answers we give to this question will be crucial for designing curricula for our student teachers to acquire the criteria for the realisations of the specialisation - effective specialist FET mathematics teacher

In the context of curriculum reform, teacher educators, education academics and academics in the mathematical sciences, who have an interest in producing specialist mathematics teachers for grades $10-12$, have a responsibility to contest for space and time in the four-year curriculum - to argue for the specialised focus, to compete for resources to project their particular 'bias and focus' into the official pedagogic identity projected from their institutions. A responsibility to research and produce criteria for novice teachers to navigate the acquisition of the recognition and realisation rules for specialist mathematical pedagogic identities. This requires the development of criteria for what constitutes 'best practice' in mathematics and mathematics teaching: a clear notion of what kind of knowledge(s) and practice(s) mathematics teachers should acquire to be in a position to put this 'best practice into practice', and how these should be acquired and co-ordinated in the teacher 


\section{Official pedagogic identities from South African policy - some implications for mathematics teacher education practice}

education programme, and who should be involved in their transmission.

The modalities of practice and knowledge discourses selected and co-ordinated in the fouryear degree curriculum do matter, and may have profound effects on the construction of new specialist mathematics teacher identities for and in South Africa, and hence on the possibility of breaking the cycle of poverty in mathematics education more broadly.

\section{References}

Adler, J. (2004). Research and maths teacher education in ten years of SAARMSTE: Trends and Challenges. In A. Buffler \& R. Laugksch. (Eds.), Proceedings of the $12^{\text {th }}$ Annual Conference of the Southern African Association for Research in Mathematics, Science and Technology Education (pp 6-15). Durban: SAARMSTE.

Adler, J., and Davis, Z. (2006). Opening another black box: Researching Mathematics for Teaching in Mathematics Education. Journal for Research in Mathematics Education, 37 (4), 270-296.

Adler, J., Slonimsky, L., \& Reed, Y. (2002). Subject-focused INSET and teachers' conceptual development. In J. Adler, \& Y. Reed (Eds.), Challenges of Teacher Development: An Investigation of take-up in South Africa (pp 135-152). Pretoria: Van Schaik Publishers.

Bernstein, B. (1977). Class Codes and Control: Volume 3 Towards a Theory of Educational Transmission. Chapter 4: On the Curriculum. (pp 79-84). London: Routledge \& Kegan Paul.

Bernstein, B. (1990). The Structuring of Pedagogic Discourse. Volume IV: Class, Codes and Control. London and New York: Routledge.

Bernstein, B. (1996). Pedagogy Symbolic Control and Identity: Theory, Research, Critique. London: Taylor and Francis.

Bernstein, B. (2000). Pedagogy Symbolic Control and Identity: Theory, Research, Critique (Revised Edition). Oxford: Rowman \& Littlefield Publishing, Inc.

Ball, D. L., \& Bass, H. (2000). Interweaving context and pedagogy in teaching and learning to teach: Knowing and using mathematics. In J. Boaler (Ed.), Multiple perspectives on teaching and learning mathematics (pp 83103). Westport, CT: Ablex.
Ball, D.L., Bass, H., and Hill, H.C. (2004). Knowing and using mathematical knowledge in teaching: learning what matters. In A. Buffler \& R. Laugksch. (Eds.), Proceedings of the $12^{\text {th }}$ Annual Conference of the Southern African Association for Research in Mathematics, Science and Technology Education . (pp 51-65). Durban: SAARMSTE

Boaler, J. (2002). The development of Disciplinary Relationships: Knowledge, Practice and Identity in Mathematics Classrooms. For the Learning of Mathematics, 22 (1), 42-47.

Castells, M. (1997). The Power of Identity - The information age: economy, society and Culture: Volume II. Massachusetts, USA and Oxford, UK: Blackwell Publishers.

DoE. (2000a). Norms and Standards for Educators in Schooling - Government Gazette No. 20844, 4 Feb 2000. Pretoria: Government Press.

DoE. (2000b). Criteria for Recognition and Evaluation of Qualifications - Government Gazette No. 21565, 22 September 2000. Pretoria: Government Press.

DoE. (2001). National Strategy for Mathematics, Science and Technology Education in General and Further Education and Training. Pretoria: Department of Education.

DoE. (2003). National Curriculum Statement for Mathematics for FET: Grades 10-12. Pretoria: Department of Education.

Ensor, P. (2000). Knowledge and Pedagogy in Initial Teacher Education. Journal of Education, 25, 161-91.

Ernest, P. (1991). The Philosophy of Mathematics Education. London, New York \& Philadelphia: Falmer Press.

Graven, M. (2002). Mathematics Teacher Learning, Communities of Practice and the Centrality of Confidence. Unpublished $\mathrm{PhD}$ Thesis. Johannesburg: University of the Witwatersrand.

Kilpatrick, J., Swafford, J., \& Findell, B. (Eds.). (2001). Adding it up: Helping children learn mathematics. Washington DC: National Academy Press.

Parker, B. (2003). Roles and Responsibilities, Institutional Landscapes and Curriculum Mindscapes: A Partial View of Teacher Education Policy in South Africa: 1990 2000. In K. Lewin, M. Samuel, \& Y. Sayed, (Eds.), Changing Patterns of Teacher Education in South Africa: Policy, Practice and Prospects (pp 16-44). Sandown: Heinemann. 


\section{Diane Parker}

Parker, D. (2004). Mathematics and Mathematics Teaching in South Africa: Challenges for the University and the Provincial Department of Education and Culture. In R. Balfour, T. Buthelezi and C. Mitchell (Eds.), Teacher Development at the Centre of Change (pp 119136). Durban: SEMI.

Parker, D. (2006) South African mathematics teacher education: Forms of knowledge and practice. In Proceedings of the 14th annual Southern African Association for Research in Mathematics, Science and Technology Education (SAARMSTE): Mathematics, Science and Technology Education: Researching the connections and connecting the researchers. 9 - 12 January 2006. Groenkloof Campus, University of Pretoria.

Parker, D. (forthcoming). Grade $10 \quad-12$ Mathematics Curriculum Reform in South Africa: A textual analysis of new national curriculum statements. African Journal for Research in Mathematics, Science and Technology Education. (forthcoming).
Parker, D. and Adler, J. (2005) Constraint or Catalyst? The regulation of teacher education in South Africa. Journal of Education, 36, 5978.

\section{Acknowledgements}

This paper is based on work supported by the National Research Foundation (SA) under the Thuthuka (Researchers in Training) programme, Grant number 2052952 - Mathematics Teacher Education. Any opinion, findings and conclusions or recommendations expressed in this material are those of the author and do not necessarily reflect the views of the National Research Foundation.

A version of the paper is to be published in $\mathrm{G}$. Anthony \& B. Grevholm (Eds.). (Forthcoming) Research on teacher education, recruitment, competencies and teachers' identity. (ICME-10 thematic afternoon conference proceedings.)

With equal passion I have sought knowledge.

I have wished to understand the hearts of men. I have wished to know why the stars shine. And I have tried to apprehend the Pythagorean power by which number holds sway about the flux. A little of this, but not much, I have achieved.

Bertrand Russell ( Autobiography) 